\title{
The long-term effects of nuclear accidents
}

\author{
R. Sjöblom \\ Waste Science \& Technology, Luleå University of Technology, Sweden
}

\begin{abstract}
The purpose of the present paper is to present some examples, based mainly on Swedish work, of late effects of nuclear accidents together with their implications and possible remedies, or absence of need for remedies. It took six years after the Three Mile Island accident before it was realized that the core was partially converted into very corrosion resistant corium which was distributed throughout the reactor system in the form of fines. It is essential that techniques for removal of such debris be developed for the Fukushima plant in order for large areas to become accessible. The ability of caesium-137 to bind irreversibly to soil material is essential in conjunction with ploughing, since it will not only imply self-shielding but also that caesium- 137 is hindered from entering the groundwater as well as plants. Disposal of top soil material may be greatly facilitated if such immobilization can eliminate the need for a top seal. However, such operations are irreversible, and knowledge of the long-term properties of the soil material must be available before any decisions can be made. Thus, previous experience, especially on the long term behaviour is essential. Such long-term results are available in Sweden from tests started already in the early 60 's. The issues have been studied in substantial detail since the level of protection has been much higher in Sweden than e. g. in Japan. Otherwise, the total fallouts are comparable in magnitude with Sweden receiving around $5 \%$ of the total from Chernobyl, and Japan receiving from Fukushima what corresponds to about $8 \%$ of that from Chernobyl, all figured as caesium-137. The distribution is much more concentrated in Japan, however. The major need for protection in Sweden relates to ash and reindeer in which areas Authority restrictions still apply. Even modest levels of caesium-137 in the bio-fuel may lead to levels in the ash that warrant consideration.

Keywords: Sweden, long-term, Chernobyl, Fukushima, caesium-137, ash, immobilization, corium, fuel debris, ploughing, landfilling, disposal.
\end{abstract}




\section{Background}

Accidents may happen, even ones with catastrophic consequences, and even though the ambition is that all conceivable efforts should be spent on preventing them. Moreover, awareness of human fallibility also leads us to include features that limit the consequences and systems for emergency action.

Loss of control of nuclear fission processes as well loss of cooling of irradiated nuclear fuel is by no means limited to the more well-known and comparatively recent cases of Three Mile Island (TMI), Chernobyl and Fukushima. Such accidents have happened earlier with smaller reactors and with less severe consequences.

It is appropriate, that the major efforts are spent on preventing accidents, and limiting their immediate consequences. But there are also long-term effects that may extend over years, decades and even centuries.

Experience on the short-term events, consequences and remedial actions is typically communicated among the teams working permanently with preparedness and radiation protection [1], but channels are much more scarce for dissemination around long-term issues. Moreover such features may be very difficult to identify in advance, since decisions on long-term issues may have to be made early in the process after an accident.

An accident like the one at Fukushima implies by necessity that resources for managing the situation become extremely strained. It might be feared, that although support of various kinds can be received from elsewhere, the possibility to dig at any depth into foreign sources and experiences may be limited.

Thus, it may be appropriate that those in possession of know-how on long-term effects document it such that it becomes available to people involved in the Fukushima work as well as in any future severe accident.

\section{Objectives}

The purpose of the present work is to compile some examples of late effects of nuclear accidents together with their implications and possible remedies, or absence of need for remedies.

The scope will be limited to that of the experience from the fallout from the USSR atmospheric nuclear bomb tests and the Chernobyl accident [2-3], and that of Swedish participation in the TMI post-accident work [4].

Actually, it is only on the order of 2000 kilometres between USSR Nova Zemlya and the northern part of Sweden, and Sweden received as much as around $5 \%$ of the total fallout from Chernobyl, figured as caesium-137 [2-3].

\section{The generation of corium at Three Mile Island}

The accident at reactor 2 at the TMI nuclear power plant near Harrisburg in Pennsylvania, USA, took place on March 28, 1979. It is a pressurized water reactor (PWR), and the primary reason for the accident was a stop of a feed-water pump for the steam generators. This lead to a shut-down of the 
reactor and to a blow-off of steam from the reactor system. Due to a misinterpretation of the situation, no water was added to the reactor tank, and as a consequence, the upper part of the fuel was left without cooling . This, in turn, lead to a temperature increase to around $1900^{\circ} \mathrm{C}$, i.e. a partial core melt-down.

It took a number of years before the full extent of the accident was realized. Still, in the year 1985, work was in progress to dissolve what was regarded as fuel debris [4], so that the reactor could be restarted. The method, albeit very efficient on un-irradiated fuel, did not work at all on the "fuel debris".

It was simultaneously discovered, that the "fuel debris" actually consisted of "corium", a solidified melt of uranium oxide, zircalloy and stainless steel (zircalloy is a zirconium-rich alloy used as cladding for the fuel).

At present, the reactor is mothballed awaiting decommissioning after the eventual cessation of operation of the twin reactor TMI-1.

The lesson learned is that even though removal of strongly radioactive matter is necessary before further decommissioning can take place, ordinary decontamination chemistries cannot be expected to work if the fuel in question has reached high temperatures.

\section{The Chernobyl accident and its consequences in Sweden}

\subsection{The accident}

The Chernobyl accident took place on April 26, 1986, after the reactor had become prompt critical during a test that was carried out in violation of a number of safety rules. "Prompt critical" means that the rate of generation of prompt neutrons is higher than that which is needed for steady state operation. (Some of the neutrons generated in a reactor are delayed, and this would normally allow a little time for a control system to hinder escalation under steady state conditions.) In addition, the reactor, of type VVER, was operated under such adverse conditions when it had a so-called positive void coefficient, meaning that it increased its power output when the temperature was increased (normally this coefficient is negative in a reactor).

The reactor exploded in the accident, and the graphite, used as a moderator for the neutrons, caught on fire. As a consequence, much of the core evaporated, and was carried to a high altitude. The fine particles were then carried away with the wind, and were preferentially deposited in conjunction with rain, as was the case e.g. in the Gävle area in Sweden. The fallout was detected within hours, and the situation interpreted and acted on at the two of the sites that were affected, Forsmark [2-3] and Studsvik [5-6]. The accident was thus communicated internationally from these sources before it was admitted by the USSR. The highest value for the surface contamination was around $200 \mathrm{kBq} / \mathrm{m}^{2}$ [2-3].

Although around $5 \%$ of the total emission of caesium-137 was deposited in Sweden, the ambition with regard to dose were kept at a level of $0.01 \mathrm{mSv}$ per year for an individual in a critical group. The value used for accident conditions was thus the same as that for normal operation for a nuclear power plant (or any other planned activity). This was and is considerably stricter than what 
has been applied in most other countries. One of the consequences of this is that authorities as well as companies have had to investigate in some detail how the doses arise and how they might be reduced.

Today, 28 years after the accident, authority oversight covers only two areas: reindeer meat and wood ash.

\subsection{Reindeer meat}

It has been known since the atmospheric tests at Nova Zemlya that reindeer meat can contain caesium-137 from fallout, especially when they feed on lichen. It grows under very meager conditions from a nutrient point of view, and thus, the potassium to caesium-137 ratio is unfavourable and the uptake is high.

Most of the reindeer slaughtered during 1986 were discarded because they were too radioactive, but during 2007-2012, this was the case for only between 0.03 and $0.18 \%$. The reasons include increasing the limit in meet to $1500 \mathrm{~Bq} / \mathrm{kg}$, changing the time for the slaughter and feeding with non-radioactive forage [7].

\subsection{Wood ash}

Initially, caesium-137 in fallout is largely picked up by vegetation, as well as in the organic matter that is usually covering the soil, at least in forested areas. Moreover, in their quest for the nutrient potassium, vegetation picks up the relative caesium in the process.

In a forested area, the dose to man from caesium-137 is roughly equally distributed between external dose from vegetation and from the ground, and dose from oral intake of berries, mushrooms and meat from primarily elk and deer, see [8] and references therein for support for this and subsequent statements.

When organic matter is combusted, caesium-137 becomes concentrated to a small fraction of the initial weight and volume. Moreover, such a process converts caesium-137 to a form that may be highly available to water phase, at least initially. Consequently, pathways that include ash constitute the most potent ones for dose to man from fallout. Efficient routes may include return of nutrients in ash to the forest, geotechnical constructions and disposal at a landfill.

Initially, it was feared that such exposures might become substantial in relation to the limit of $0.01 \mathrm{mSv}$ per year, and this gave rise to what is now regulation SSMFS 2012:3. As it turned out, doses became much lower than what was feared initially. The calculated dose from return of nutrients in ash to the forest became lower already when it was realized that animals graze over much larger areas than those possibly considered for spreading of ash. The calculated as well as the actual dose from migration by groundwater movement was found to be much less than initially anticipated for reasons presented in Section 6 .

However, ash is still being monitored for activity content, and caution is still applied for some of the ash e.g. in conjunction disposal at a landfill, and when it is being used in geotechnical constructions. 


\subsection{Farming}

Ash is not used as a fertilizer to agricultural land on a commercial base in Sweden, but such practices may occur in private gardens. Crops containing water dominate with regard to dose, and the most efficient pathway is probably through potatoes.

For Swedish conditions, the external dose was efficiently diminished to insignificant levels after the soil had been ploughed. As a rule of thumb, it may be estimated that the dose rate becomes halved for each three centimetres of soil cover added. No limits have been applied to the use of agricultural land in Sweden as a result of the Chernobyl accident.

\section{Behaviour of caesium in soil and ash}

The behaviour of sorbed caesium-137 in soil and porewater is frequently described by the following equation:

$$
\mathrm{S}=\mathrm{K}_{\mathrm{d}} \cdot \mathrm{C}
$$

where

$\mathrm{S}=$ the sorbed activity in $\mathrm{Bq}$ per $\mathrm{kg}$ solid,

$\mathrm{C}=$ the activity concentration in $\mathrm{Bq}$ per litre, and

$\mathrm{K}_{\mathrm{d}}=$ the distribution coefficient in litres per $\mathrm{kg}$.

The rate of transport of caesium in soil, $\mathrm{v}_{\mathrm{Cs}-137}$, may then readily be estimated from the known rate of water flow, $\mathrm{v}_{\mathrm{w}}$ and the $\mathrm{K}_{\mathrm{d}}$ determined in a simple equilibrium test:

$$
\mathrm{v}_{\mathrm{Cs}-137}=\mathrm{v}_{\mathrm{w}} / \mathrm{R}_{\mathrm{f}}
$$

where

$$
\mathrm{R}_{\mathrm{f}}=\rho_{\mathrm{b}} \cdot \mathrm{K}_{\mathrm{d}} / \mathrm{n}_{\mathrm{e}}
$$

and

$\rho_{\mathrm{b}}=$ the bulk density in $\mathrm{kg}$ per litre, and

$\mathrm{n}_{\mathrm{e}}=$ the effective porosity of the soil at saturation.

However, such a model, although extensively used, may actually be as misleading as it is simple, at least for long-term events. An example of the variation of $\mathrm{K}_{\mathrm{d}}$ over time is shown in Figure 1. As can be seen in the Figure, equilibrium conditions have not been reached even after a couple of weeks.

Actually, the $\mathrm{K}_{\mathrm{d}}$-model presupposes that the caesium ions occur only in exchangeable positions, and that the exchange takes place much more rapidly than the duration of the experiment.

In reality, caesium - as well as potassium - is present in soil and ash in several different "compartments", e.g. dissolved in the pore water, exchangeable, non-exchangeable and as bonded to minerals. 


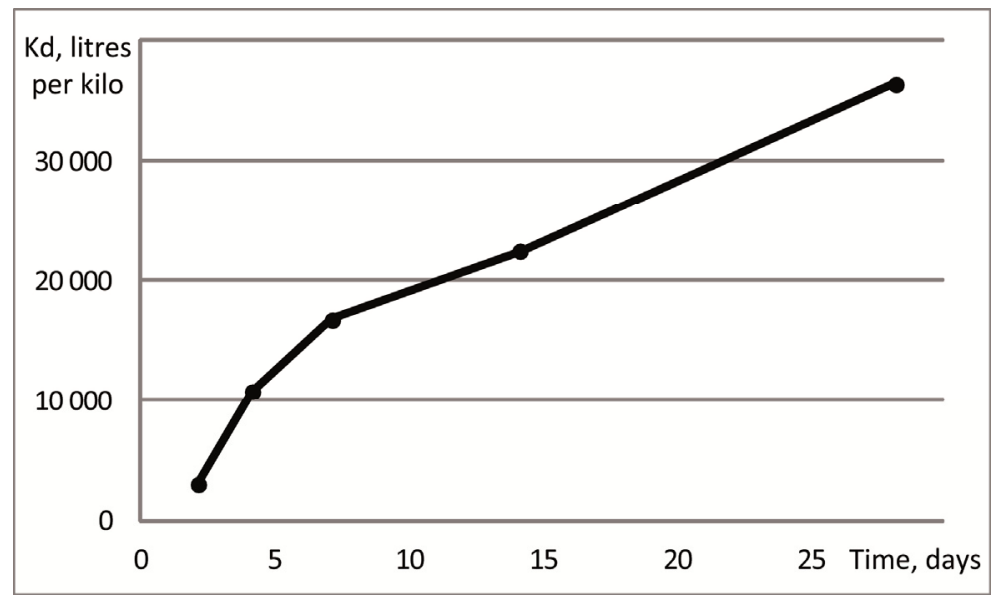

Figure 1: Distribution coefficient for caesium-137 versus time on the $<0.063 \mathrm{~mm}$ fraction of a soil material, modified from [9].

Of particular interest in this regard is the so-called "frayed edges" of micas undergoing weathering, see Figure 2. Micas with potassium between the silicate sheets in their structures constitute an important source for potassium in many soils. Caesium has a higher tendency than potassium to be incorporated in such minerals, and there is also a strong entropy gain involved when potassium becomes replaced with caesium in those positions. However, the rate of exchange in is much lower than that for exchangeable caesium.

Laboratory data on distribution coefficients for caesium-137 in soil show large variations, and values from 10 to 30,000 litres per kilogram have been published [11-13]. There is a strong correlation with clay content and cation exchange capacity. No long-term laboratory data have been found in the literature, but the experience from contamination of land during the efforts to make the atomic bombs during the second world war, indicate e. g. values on the order of 69,000 to 370,000 litres per kilo for a site at Oak Ridge [14].

Perhaps the clearest information on this issue can be found in [15], which is based on data from the fallout from Chernobyl as well as data from soil deliberately supplied with caesium-137 in the year 1961 (in order to simulate fallout from atmospheric bomb tests). It was found that the rate of migration of caesium-137 in soil may be as low as on the order of one millimetre per year after a few decades. This is substantially different from the migration rate in conjunction with the fallout which was on the order of around several centimetres during the first several days.

Moreover, it was discovered in [15] that whilst clay provides substantially more retention during the first several years, clayey and sandy soils were found to be about equal after a few decades. The low rates of migration were correlated with substantial resistance to extraction. After a few decades, most of the caesium-137 was resistant to all extracting agents tested except nitric acid, and this acid dissolved only around half of the caesium-137. 


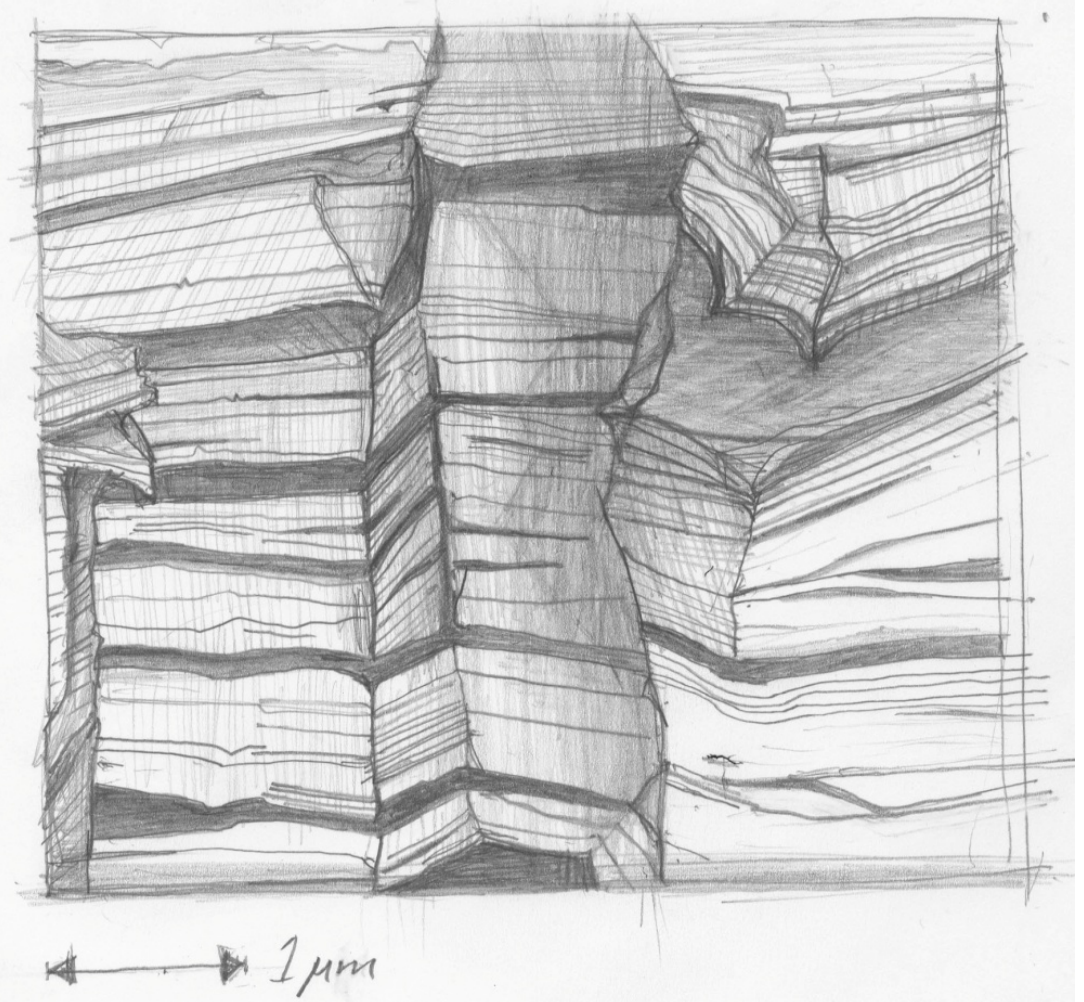

Figure 2: $\quad$ The frayed edges and spalled layers of naturally weathered mica (biotite). The available weathered surface may be many times that of an un-weathered particle. Drawing after a photograph in [10].

It should be noted that the uptake of caesium-137 by living organisms is not a simple function of the concentration of caesium alone. Caesium is picked up in conjunction with the uptake of potassium, and for a constant level of caesium in water, the uptake decreases with increasing concentration of potassium [16].

Thus, for a lake low in nutrients, addition of ash containing caesium-137 may actually lower the uptake of caesium although its concentration in the water is increased. The reason for this is that bio-ash typically contains high levels of potassium.

\section{Implications for the Fukushima accident}

\subsection{The accident}

The Fukushima accident occurred during March 11 and the subsequent several days. The primary cause was a magnitude 9.0 earth-quake $130 \mathrm{~km}$ off the Pacific coast of Honshu, which is the main island of Japan. It was followed after 
about 50 minutes by a large tsunami. The earth-quake caused scrams (rapid stops) of the reactors 1-3, which were in operation. Even after such a stop, the fuel in the core produces a lot of heat due to decay of short-lived radioactive fission products. The earth-quake lead to a black-out of the electric grid after which the electricity for the coolant pumps was maintained by diesel generators. They were, however, disabled by the tsunami, and after that power was supplied from batteries which then became discharged during several hours.

After the loss of cooling, water started to boil in the reactor vessels of reactors 1-3 and in the fuel pools, including the pool at reactor 4 . This lead to a lowering of the water level so that the top of the fuel did not get any cooling. Such un-cooled fuel can reach a very high temperatures, leading to reaction with steam and generation of hydrogen, release of radio-nuclides, and at least partial melt-down of the fuel. Large explosions from hydrogen mixed with air took place at reactors 1 and 3 [17].

Even though there exists a lot of publications on the accident, information is fragmented, and there probably exists a lot still to be found out. An excellent compilation, based largely on detective work, can be found in [18]. It estimates that the total emission of caesium-137 from the Fukushima accident corresponds to $43 \%$ of that from Chernobyl. However, only $18 \%$ of this was deposited on land in Japan, thus amounting to $8 \%$ of the total of Chernobyl, and thus actually somewhat comparable to the around 5\% mentioned above for Sweden. The areal distribution is quite different, however, since the plume in Japan did not reach high altitude. Thus, large areas in Japan are contaminated with much higher levels of caesium-137 than in the case of Sweden. However, the protection levels considered and utilized are also much higher. For instance, [18] reports that it is the ambition of the Government in Japan to reduce the dose to an individual in the public to $<20 \mathrm{mSv}$ per year, with a long-term target of keeping the exposure below $1 \mathrm{mSv}$ per year. This might be compared with the Swedish target mentioned above which is $<0.01 \mathrm{mSv}$ per year.

\subsection{Fuel debris and corium}

The reactors and fuel pools at the Fukushima site are now at a state of cold shut-down and steady state, and planning has been made for the subsequent steps [19]. In many areas of the plants, dose rates are high until fuel and "fuel debris" has been removed. It is being realized, cf. Section 3, that "fuel debris" is actually "material in which fuel and its cladding tubes etc. have melted and resolidified" and that "research and development necessary for the removal of fuel debris" is included in the planning [19].

Previous experience, cf. Section 3, indicates that this may be a rather daunting undertaking, since none of the chemistries at the time (1985) dissolved corium, and since titanium dioxide, which is closely related chemically to zirconium dioxide, has a solid reputation in geochemistry for incorporating various elements into a product that may be extremely resistant to weathering and corrosion. 


\subsection{Ploughing versus removal and disposal}

Remedial actions have been discussed in many forums, including the ISTC/STCU Symposium and Seminar which was co-organised by the Japanese government, the OECD Nuclear Energy Agency (NEA) and the International Atomic Energy Agency (IAEA), and which took place in Tokyo, Japan, during February 3-4, 2012. It focused on the experience from Ukraine, Russia and Belarus after Chernobyl. It was anticipated amongst other issues that surface soil would have to be removed over large areas, and be deposited in repositories similar to those for low-level waste from operation of nuclear power plants.

It appears that a somewhat different balance is struck in [18] where considerably more emphasis is put on ploughing. Such a practice may be relatively efficient to lower the external dose since, as a rule of thumb, a soil cover of $3 \mathrm{~cm}$ decreases the dose rate from caesium-137 by a factor of two. Nonetheless, the method will not be sufficiently efficient for high levels of contamination, and [18] mentions a limit of $5000 \mathrm{~Bq} / \mathrm{kg}$ under which ploughing and other agricultural practices may be applied (e.g. choice of crops and potassium fertilization).

The Swedish experience clearly indicates that the feasibility of any such ploughing should be strongly dependent on the ability of the particular soil to stabilize caesium-137. The geology of Japan is very complex [20] as well as its soils. Some information search has indicated that it is likely that the soil around Fukushima may have similar favourable properties as those in Sweden in permanently absorbing caesium-137 in the long term.

\section{Discussion and conclusions}

We have had modern "full-size" nuclear power reactors since around the year 1970. Since then, three major accidents have occurred, and for different reasons. Of course, we all hope that the latest one will also be the last. Nonetheless, work is constantly in progress to improve the safety, and to be prepared just in case. Justifiably, this preparedness focuses on emergency action.

However, certain long-term issues need also be included in the planning, and in the present paper, the issues of corium formation and caesium-137 retention have been illuminated.

Removal of fuel and fuel debris is essential early in the decommissioning process in order to lower the dose rate and thereby to allow access for continued work. Fuel debris/corium is treacherous in this regard compared to the bulk fuel in that is can be expected to be distributed throughout the damaged systems, and thus block access to large areas (because of its high dose rate). Possibly, much of the debris might be removed by mechanical means, but is should not be expected that this will be sufficient. Efficient chemical methods are likely to be different from those developed for ordinary primary systems decontamination in especially view of the extremely chemically resistant zirconium dioxide.

The design of a landfill is strongly dependent on the properties of the waste, and here soil is very different from reactor waste in that it does not subside, and 
especially not differentially, and requires a minimum of engineered structures. Moreover, if it can be proven that caesium-137 does not leach, then it may suffice with only a cover for protection (e.g. shielding of radiation) and no seal.

Ploughing may be appropriate if the soil will provide sufficient shielding against external radiation, and if the caesium-137 is sufficiently inaccessible in order not to be taken up by the plants.

It is frequently recommended that clays having a high cationic exchange capacity be used to retard the migration of caesium-137. This may be expected to work well for the short term, but is probably of little benefit for the long term. Instead, it should be assured that the caesium-137 has access to minerals to which it can bind permanently. By the very nature of the issue, such tests must be carried out during long times, or perhaps preferably, be carried out using natural or anthropogenic analogues.

The Swedish work, although not represented in the meeting mentioned above (see Section 7.3) may be of interest in this regard since long-term events have been included, and since the protection has been applied to very low dose levels.

Some constraints regarding decisions and timing are crucial. Ploughing is irreversible, and it is necessary to know before any such operation that the caesium-137 will become reasonably stabilized. The same applies to disposal, if the inherent stabilization capability of the soil material is to be utilized.

It took six years to realize that fuel debris at TMI was actually corium, and it took twenty years for what is now the Swedish Radiation Safety Authority to issue regulations regarding caesium-137 in ash. It should be possible to keep such times much shorter in the future provided that the lessons learned from incurred events are fully realized and that appropriate 'R\&D efforts' are carried out as a precautionary measure rather than as a reaction to any future event.

\section{Acknowledgements}

The present work has been supported by the following organizations: Econova AB, ENA Energi AB, Mälarenergi AB, Svenska Energiaskor AB, (which translates to: "Swedish Energy Ashes Inc."), [The Swedish] Thermal Engineering Research Institute (Värmeforsk) and Angpanneföreningen's Foundation for Research and Development (Ångpanneföreningens Forskningsstiftelse).

\section{References}

[1] Actions to Protect the Public in an Emergency due to Severe Conditions at a Light Water Reactor. IAEA, May, 2013.

[2] Moberg, L., editor, The Chernobyl fallout in Sweden. Results from a research programme on environmental radiology. The Swedish Radiation Protection Institute (now the Swedish Radiation Safety Authority), 1991. 
[3] Moberg, L., The nuclear accident at Chernobyl, a summary fifteen years after the accident. (Swedish title: Kärnkraftsolyckan $i$ Tjernobyl. En sammanfattning femton år efter olyckan). SSI Rapport 2001:07, Stockholm, 2001. Available from the Swedish Radiation Safety Authority, Stockholm.

[4] Sjöblom, R., Olson, P. M., Parke, J. M. \& Schneidmiller, D., Post-accident chemical decontamination method development, Final Report. EPRI Research Project RP 2012-8, EPRI Report number EPRI-NP-4999, January 1987 (Concerns the primary system in the reactor Three Mile Island 2).

[5] Devell, L., Tovedal, H., Bergström, U., Appelgren, A., Chyssler, J. \& Andersson, L., Initial observations of fallout from the reactor accident at Chernobyl. Letter to nature 321, May 15, 1986.

[6] Devell, L., Composition and properties of plume and fallout materials from the Chernobyl accident. In Moberg, L., Editor. The Chernobyl fallout in Sweden. Results from a research programme on environmental radiology. The Swedish Radiation Protection Institute (now the Swedish Radiation Safety Authority), 1991.

[7] Åhman, B., Development, monitoring and actions regarding radioactive caesium in reindeer after the Chernobyl accident. (Swedish title: Utveckling, övervakning och åtgärder när det gäller radioaktivt cesium $i$ renar efter Tjernobylolyckan). SSI Rapport 2005:17, October, 2007. (Available from the Swedish Radiation Safety Authority).

[8] Sjöblom, R., Caesium-137 in ash from combustion of bio-fuels. Application of the regulations (now SSMFS 2012:3) from the Swedish Radiation Safety Authority. (Swedish title: Cesium-137 $i$ aska frän förbränning av biobränslen. Tillämpning av Strålsäkerhetsmyndighetens regler.) Värmeforsk, Report 1080, January, 2009. (Openly available at www.varmeforsk.se).

[9] Funebo, T., Caesium sorption/Desorption behaviour on soil. Diploma thesis for the degree of Master of science in Chemical Engineering. Department of Nuclear Chemistry, Chalmers University of Technology, Göteborg, 1995.

[10] Graf, H., Factors of mica transformation. In "Potassium in soil". Proceedings of the 9th colloquium of the International Potash Institute held at Landshut / Federal Republic of Germany, 1972. Printed by the International Potash Institute.

[11] Understanding variation in partition coefficient, $\mathrm{Kd}$, values. Volume I: The Kd Model, Methods of Measurement, and Application of Chemical Reaction Codes. United States Environmental Protection Agency, Office of Air and Radiation, Report EPA 402-R-99-004A, August 1999.

[12] Understanding variation in partition coefficient, $K d$, values. Volume II: Review of Geochemistry and Available Kd Values for Cadmium, Caesium, Chromium, Lead, Plutonium, Radon, Strontium, Thorium, Tritium (3H) and Uranium. United States Environmental Protection Agency, Office of Air and Radiation, Report EPA 402-R-99-004B, August 1999. 
[13] Understanding variation in partition coefficient, $K d$, values. Volume III: Review of Geochemistry and Available Kd Values for Americium, Arsenic, Curium, Iodine, Neptunium, Radium, and Technetium. United States Environmental Protection Agency, Office of Air and Radiation, Report EPA 402-R-04-002C, July 2004.

[14] Cesium-137 in the environment: radioecology and approaches to assessment and management. NCRP Report No 164. National Council on Radiation Protection and Measurements. Bethesda, MD 20814-3095, USA. 2007.

[15] Forsberg, S., Behaviour of ${ }^{137} \mathrm{Cs}$ and ${ }^{90} \mathrm{Sr}$ in agricultural soils. Influence of ageing and soil type on availability, migration and plant uptake. Doctoral thesis. The Swedish University of Agricultural Sciences, Agraris 212, 1999.

[16] Håkansson, L., Modelling radiocesium in lakes and coastal areas - new approaches for ecosystem modellers. Kluwer Academic Publishers, 2000.

[17] Stohl, A., Seibert, P., Wotawa, G., Arnold, D., Burkhart, J. F., Eckhardt, S., Tapia, C., Vargas, A. \& Yasunari, T. J., Xenon-133 and caesium-137 releases into the atmosphere from the Fukushima Dai-ichi nuclear power plant: determination of the source term, atmospheric dispersion, and deposition. Atmos. Chem. Phys., 12, pp. 231-2343, 2012.

[18] Remediation of large contaminated areas off-site the Fukushima Dai-ichi nuclear power plant. IAEA, NE/NEFW/2011, 7-15 October, Japan, 2011.

[19] Mid-and-long-Term Roadmap towards the Decommissioning of Fukushima Daiichi Nuclear Power Station Units 1-4. Nuclear Emergency Response Headquarters Government and TEPCO's Mid-to-Long Term Countermeasure Meeting. TEPCO. December 21, 2011.

[20] Hashimoto, M., editor, Geology of Japan. Kluwer Academic Publishers, 1991. 